\title{
The ability of tree stems to intercept debris flows in forested fan areas: A laboratory modelling study
}

\author{
Francesco Bettella, ${ }^{1}$ Tamara Michelini, ${ }^{1}$ Vincenzo D’Agostino, ${ }^{1}$ Gian Battista Bischetti ${ }^{2,3}$ \\ ${ }^{1}$ Department of Land, Environment, Agriculture and Forestry, University of Padua, Legnaro (PD); ${ }^{2}$ Department of \\ Agricultural and Environmental Sciences, University of Milan, Milan; ${ }^{3}$ Centre of Applied Studies for the Sustainable \\ Management and Protection of Mountain Areas, University of Milan, Brescia, Italy
}

\begin{abstract}
Debris flows are one of the most common geomorphic processes in steep mountainous areas. The control of their propagation on alluvial fans is fundamental; valley bottoms are usually characterised by high damage potential because they contain concentrations of inhabitants and infrastructure. It is well known that forests have a protective function in that they reduce the triggering of debris flows, as well as hinder their motion and promote deposition, but a quantitative assessment of these effects is still lacking. Using laboratory experiments that simulate debris-flow depositional processes, this research investigated the ability of forests to reduce debris-flow runout and depositional area. The experiments considered two different forest types, high forests and coppice forests, and four volumetric concentrations of sediment $(0.50$, $0.55,0.60$, and 0.65$)$. The results confirmed that the sediment concentration of the flow is a key factor in determining the geometry of the deposits. On the other hand, forests can reduce debris-flow runout distance and, in general terms, affect the characteristics of their deposits. The results showed that vegetation appear to reduce debris-flow motion especially when the debris-flow kinematic load at the fan apex is low. About the sediment concentration of the mixture, high forest did not exhibit a clear behaviour while
\end{abstract}

Correspondence: Francesco Bettella, Department of Land, Environment, Agriculture and Forestry (TeSAF), University of Padua, viale dell’Università 16, 35020 Legnaro (PD), Italy.

Tel.: +39.0498.272700 - Fax: +39.0498.272686.

E-mail: francesco.bettella@unipd.it

Key words: Debris flows; protective forests; protection forests; protective function; natural hazards.

Acknowledgements: the research was granted by the Junior Research Grant Università degli Studi di Padova, year 2015, prot. CPDR152771 (Experimental analysis on SuDS: performance and effectiveness) and by MIUR ex $60 \%$ founds (2016).

Received for publication: 3 May 2017.

Accepted for publication: 21 October 2017.

CCopyright F. Bettella et al., 2018

Licensee PAGEPress, Italy

Journal of Agricultural Engineering 2018; XLIX:712

doi:10.4081/jae.2018.712

This article is distributed under the terms of the Creative Commons Attribution Noncommercial License (by-nc 4.0) which permits any noncommercial use, distribution, and reproduction in any medium, provided the original author(s) and source are credited. coppice forest appears to promote significant deposition at all of the tested concentrations, and this effect increases with the solid concentration (reductions in runout between approximately $20 \%$ and $30 \%$ at $C_{\mathrm{V}=0.50}$ and $C_{\mathrm{V}=0.65}$, respectively, were observed). Due to their higher tree density, in fact, coppice forests seem to have a better protective effect than the rigid trunks of high forest trees. For this last type of forest, a relationship between the $H / L$ ratio, which represents energy dissipation, have been found and compared with the scenario without forest.

\section{Introduction}

Debris flows are one of the most common geomorphic processes in steep mountainous areas (Ancey, 2001), and they are responsible for losses of human lives and economic damages on a worldwide basis every year.

Their destructive potential can decrease due to processes that promote deposition and thus reduce the travel distance: i) reductions in excess pore fluid pressure (Hutchinson, 1986); ii) increases in the viscoplastic yield strength (Coussot and Proust, 1996); iii) increases in grain collision stresses (Takahashi, 1991); and iv) increases in grain contact friction and the concentration of friction at flow margins (Major and Iverson, 1999).

The length travelled by a debris flow on an alluvial fan from the initiation of the flow to the lowest point of the deposits (i.e., the runout distance), is the most critical issue in the delineation of areas at risk from debris flows (D'Agostino et al., 2010), and several empirical methods have consequently been suggested to predict it (e.g., Rickenmann, 2005; D'Agostino et al., 2010; Scheidl et al., 2013). Generally, runout is recognised to depend mainly on topography (i.e., the slope, width, and length of the upstream channel and the slope of the outflow plain) and debris-flow volume (e.g., Takahashi, 1991; Rickenmann, 1999; Berti and Simoni, 2007). In addition, the promotion of debris-flow deposition and the geometry of the deposits, such as runout, thickness, and the widths of levees and lobes, are strongly affected by the presence of forests and their management (Michelini et al., 2016).

Standing trees increase flow resistance, suppressing debrisflow motion and favouring the deposition of debris-flow material within a shorter distance (May, 2002; Ishikawa et al., 2003; Fidej et al., 2015). Moreover, woody debris can form woody dams within depositional areas, promoting the stopping of solid material.

Forests are recognised to reduce the probability of debrisflow-triggering landslides (Schmidt et al., 2001; Roering et al., 2003), thus avoiding the deposition of debris flows and other mass transport phenomena (Schmidt et al., 2001; Roering et al., 2003; Guthrie et al., 2010). However, although several extensive research projects on Alpine forests and their protective functions have been conducted (Brang et al., 2006), the effect of trees on the 
morphologies of debris-flow deposits is still poorly understood, and only a few studies have considered forests and their structures within alluvial fans (e.g., May, 2002).

Currently, the main methods to model debris-flows travel distance are of the empirical-statistical and analytical types (Rickenmann, 2005). Empirical-statistical methods are based on regression analysis of data from past debris-flow events to define relationships between factors such as runout length and sediment volume. Due the difficulties involved in studying debris flows at the field scale, physical scale-model experiments are considered to be very helpful for understanding the runout of hillslope debris flows (Scheidl et al., 2013), and several different scale laboratory experiments have been carried out to simulate debris flows (e.g., Major and Iverson, 1999; D'Agostino et al., 2010; Hürlimann et al., 2015; de Haas, 2015). The majority of these studies have focused on the rheology and flow behaviour of debris flows and the formation of frontal accumulations of coarse debris. Few studies have instead focused on the relationship between debris-flow features and vegetation in alpine fans or in small-scale laboratory experiments, while none of the existing researches have attempted to integrate the presence of forests into simulations of debris flows.

In this study, laboratory experiments have been conducted to investigate the effects of forest type on runout distance and deposit topography.

The experiments simulated three different scenarios: i) fan without elements; ii) fan with a high forest; and iii) fan with a coppice forest. The goals of this investigation are to verify the importance of forests and to quantitatively assess the effects of forest type on debris flow deposition.

\section{Materials and methods}

A series of laboratory experiments involving water-sediment mixtures were carried out, focusing on the role of forests in the reduction of debris-flow movement. A total of 29 runs were performed using the small-scale flume of the Department of Agricultural and Environmental Sciences - Production, Land, Agricultural, and Energy at the University of Milan.

\section{Experimental setup and procedure}

The laboratory flume consists of metal sheets, and its bottom is roughened with crosshatched metal sheets to reproduce the channel roughness (the thickness of the elements is approximately equal to $2 \mathrm{~mm}$ ). The model is made up of three parts, specifically: i) a 0.2 -m-long, 0.15-m-wide, and 0.40-m-deep storage tank in the upper part; ii) a 2.00-m-long, 0.15-m-wide, and 0.40-m-deep tilting flume with a variable inclination that can be adjusted within the range of $15^{\circ}$ to $45^{\circ}$ from the horizontal; iii) a tilting depositional surface with a variable inclination that can be adjusted within the range of $0^{\circ}$ to $10^{\circ}$ from the horizontal and is located at the toe of the experimental channel. The depositional surface allows observation of the deposit characteristics, and some threaded holes that are distributed on a grid with a spacing of $10 \mathrm{~cm}$ allow the placing of vertical elements to simulate the presence of trees. The inclination of the flume and the depositional surface were set to $20^{\circ}$ and $3^{\circ}$, respectively. A sketch of the experimental setup is displayed in Figure 1A. For each experiment, the granular material was weighed and mixed in a bucket with water to obtain $4000 \mathrm{~cm}^{3}$ of mixture. The mixture was then loaded into the head box, where a homogeneous consistency was produced by mixing with a drillmounted paint mixer. The gate was then instantaneously opened manually. The experimental procedure was the same during each experiment.

\section{Scaling conditions and flow regimes}

Many difficulties in scaling exist in the physical modelling of debris flows (Ishikawa et al., 2008; Scheidl et al., 2013; Iverson, 2015) due to the complex behaviour of debris flows, which includes scale-dependent interactions between the solid and the fluid phase. Dynamic similarity between natural and small-scale debris flows is likely impossible to obtain (Iverson et al., 2010), as small-scale debris flows are very strongly affected by the yield strength, viscous flow resistance, and grain inertia, whereas the effects of pore fluid pressure are very weak.

A common approach to compare experiments and field observations is based on hydrodynamic approaches, assuming geometric as well as simple kinematic similarity (Scheidl et al., 2013). In small-scale debris flow simulation, scaling limits are mainly due to a larger effect of viscous shear resistance and cohesion and a smaller effect of excess pore-fluid pressure respect to a real debris flow (Iverson, 2015). In addition, as reported by Scheidl (2013), full dynamic similarity of all forces ... is not feasible by using the same fluid with the same viscosity. Small-scale experiments, however, make it possible to carry out a large number of observations using a wide range of configurations, making them very useful for studying debris-flow phenomena, which are very difficult to observe at full-size scales (de Haas et al., 2015). In addition, despite the scaling simplifications involved, laboratory simulations can provide a good approximation of reality in some cases, allowing the generalisation of the results to the actual scale. In this respect, D'Agostino et al. (2010) and de Haas et al. (2015) conducted their studies with apparatus and procedures similar to those used here.

In this study, the geometric similarity of the length scale ratio value between the prototype $\left(l^{*}\right)$ and the laboratory $(l)$ length was set to 50. To characterise the flow regime, a set of dimensionless

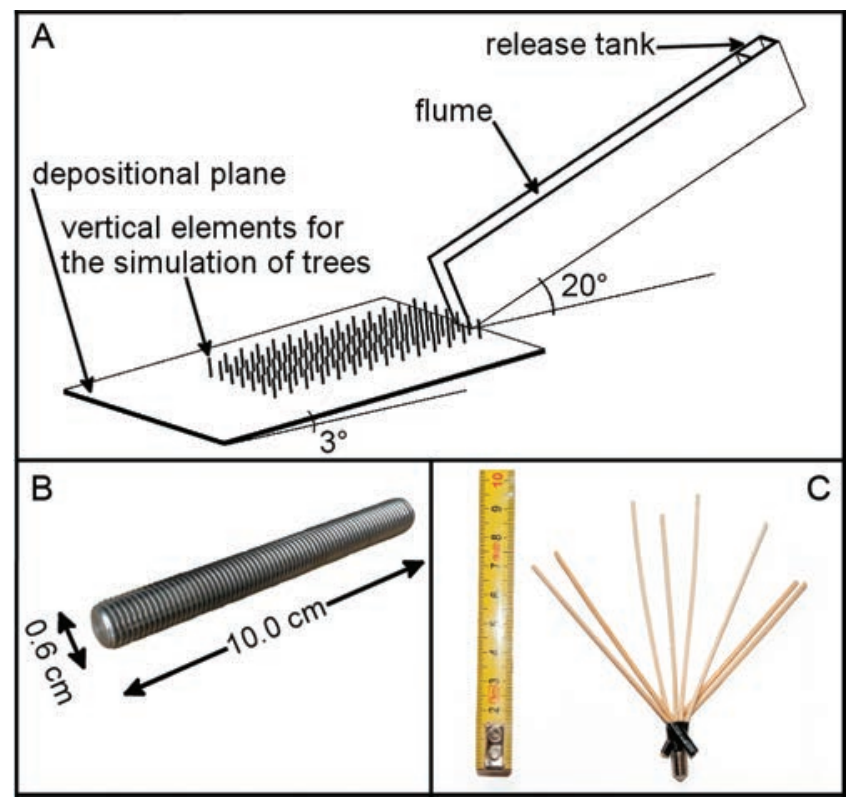

Figure 1. Sketch of the experimental setup (A) and the vertical elements used for the simulation of high forests (B) and coppice forests $(\mathbf{C})$. 
parameters was proposed by different authors and reported by de Haas et al. (2015) (Table 1). These parameters allow comparison between debris flows of different sizes and scales, enabling quantitative assessment of the similarity between the flow regimes of experimental and natural debris flows (de Haas et al., 2015). Iverson (1997), based on experiments using cohesionless dry flows containing unimodal spherical particles, defined the boundaries of the dimensionless parameters where one force dominates the other. Parsons et al. (2001), based on experimental data on water-saturated small-scale debris flows, suggested reducing the boundary between frictional forces and viscous forces to friction number $\mathrm{NF}>100$ for the flow body and NF $>250$ for the flow front. These results have been confirmed by de Haas et al. (2015), who have found that the boundary proposed by Parsons et al. (2001) provides a more accurate description of the flow regime of their experimental debris flows. To characterise the flow regimes in our tests, the Bagnold number NB, the Savage number NS, and the friction number NF were calculated.

\section{Debris-flow material}

The bulk mixtures used in the tests were obtained by mixing water and dry solid material obtained from a deposit of a real debris flow that occurred along Gadria creek (Silandro, Bolzano) in summer 2014 and passed through a sieve with 31.5-mm openings. The sample were initially oven-dried for $48 \mathrm{~h}$ at $110^{\circ} \mathrm{C}$ and remixed. Measurements of the bulk density of the solid material $\left(\rho_{s}\right)$ resulted in an average value of $2.632 \mathrm{~kg} \mathrm{~m}^{-3}$. Figure 2 reports the relative frequency distribution and the main statistical parameters of a sieve analysis of the sediment, which was performed in the laboratories of the CNR-IRPI of Padua (National Research Council of Italy - Research Institute for Geo-Hydrological Protection). The interstitial viscosity (Table 1) was estimated by means of the Thomas formula (1965).

\section{Simulation scenarios}

All of the laboratory tests included a constant total volume of the mixture, whereas we changed the water contents from $35 \%$ to $50 \%$ (by weight) to obtain four sediment volumetric concentrations, $C_{\mathrm{V}}: 0.50,0.55,0.60$, and 0.65 . Three different scenarios were simulated on the depositional plane in order to explore the effects of forest structure on the behaviour of debris flows: i) free depositional surface (i.e., without elements); ii) the presence of rigid elements distributed on a grid to simulate a high forest; iii) the presence of groups of flexible elements to simulate a coppice forest. A high forest was simulated with rigid steel screws that were $10 \mathrm{~cm}$ long and had a diameter of $0.6 \mathrm{~cm}$ (Figure 1B). To represent shoot flexibility, each stump in the coppice forest was simulated using 8 pieces of wicker $6-8 \mathrm{~cm}$ long and $0.2 \mathrm{~cm}$ in diameter (Figure 1C). These elements allowed the simulation of a forest

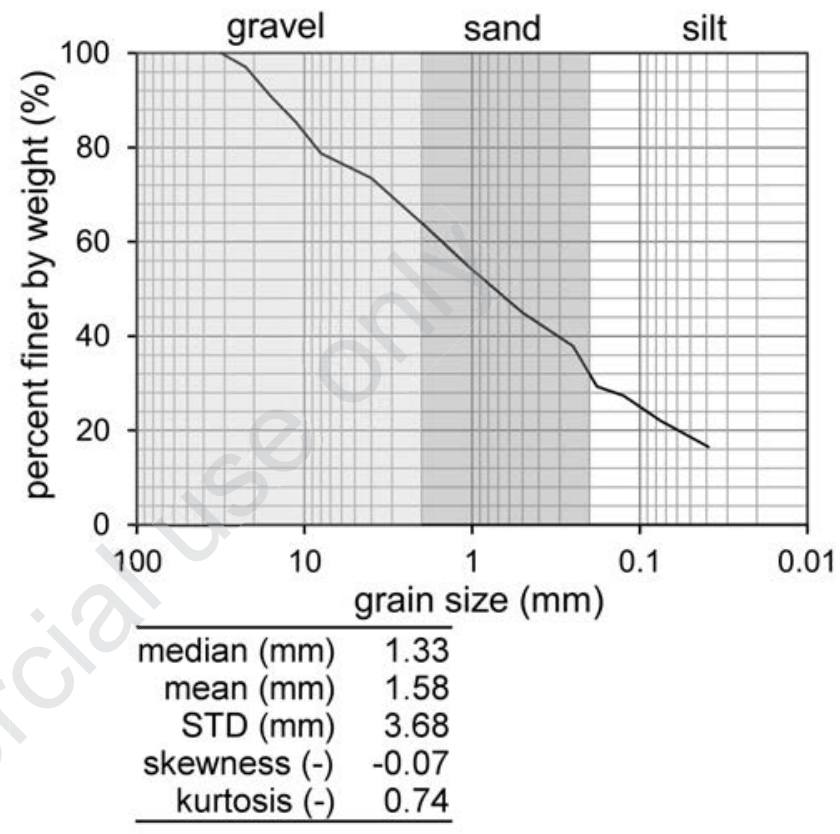

Figure 2. Results of a grain-size analysis of the solid material used in the laboratory tests sampled from a real event deposit that occurred along Gadria creek. The panel above shows the relative frequency distribution; the panel below shows the main statistical parameters (STD is the standard deviation).

Table 1. Comparison between dimensional and dimensionless indexes characterising debris flows simulated in this study and reported in the literature (de Haas et al., 2015).

\begin{tabular}{|c|c|c|c|c|c|}
\hline Parameter & Symbol (unit) & l-scale debri & de Haas et al. (2015) & $\begin{array}{l}\text { Large-scale } \\
\text { debris flow } \\
\text { USGS }\end{array}$ & $\begin{array}{l}\text { Typical range } \\
\text { of real debris } \\
\text { flow }\end{array}$ \\
\hline $\begin{array}{l}\text { Physical parameters } \\
\text { Mean diameter } \\
\text { Flow height } \\
\text { Flow velocity } \\
\text { Flow shear rate } \\
\text { Solid density } \\
\text { Solid volumetric concentration } \\
\text { Liquid volumetric concentration } \\
\text { Interstitial fluid viscosity } \\
\text { Friction angle }\end{array}$ & $\begin{array}{c}\sigma(\mathrm{m}) \\
H(\mathrm{~m}) \\
u\left(\mathrm{~m} \mathrm{~s}^{-1}\right) \\
\gamma\left(\mathrm{s}^{-1}\right) \\
\rho_{s}\left(\mathrm{~kg} \mathrm{~m}^{-3}\right) \\
\mathrm{Cv}(-) \\
\mathrm{CW}(-) \\
\mu(\mathrm{Pa} \mathrm{s}) \\
\phi\left(^{\circ}\right)\end{array}$ & $\begin{array}{c}0.00165 \\
0.006-0.040^{*} \\
1.14-19.3^{\circ} \\
48-121 \\
2632 \\
0.50-0.65 \\
0.35-0.50 \\
0.0013-0.0014 \\
35\end{array}$ & $\begin{array}{c}0.0005-0.002 \\
0.005-0.018 \\
0.9-2.9 \\
105-371 \\
2650 \\
0.35-0.59 \\
0.65-0.41 \\
0.001-0.0035 \\
42\end{array}$ & $\begin{array}{c}0.001 \\
0.1 \\
10 \\
100 \\
2700 \\
0.6 \\
0.4 \\
0.001 \\
40\end{array}$ & $\begin{array}{c}10^{-5}-10 \\
0.1-10 \\
0.1-20 \\
1-100 \\
2500-3000 \\
0.4-0.8 \\
0.2-0.6 \\
0.001-0.1 \\
25-45\end{array}$ \\
\hline $\begin{array}{l}\text { Dimensionless parameters } \\
\text { Savage number } \\
\text { Bagnold number } \\
\text { Friction number }\end{array}$ & $\begin{array}{l}N S \\
N B \\
N F\end{array}$ & $\begin{array}{c}0.007-0.362 \\
153-803 \\
1069-15428\end{array}$ & $\begin{array}{c}0.17-2.25 \\
37-1589 \\
141-2760\end{array}$ & $\begin{array}{c}0.2 \\
400 \\
2000\end{array}$ & $\begin{array}{l}10^{-7}-100 \\
10^{0}-108 \\
10^{0}-105\end{array}$ \\
\hline
\end{tabular}

${ }^{*}$ At the flume outlet; ${ }^{\circ}$ in the flume. 
stand having the characteristics described in Table 2. The elements allowed the simulation of real forests with a density of 400 trees per hectare, a tree diameter of $0.30 \mathrm{~m}$ for the high forest scenario (with a basal area equal to $28 \mathrm{~m}^{2} \mathrm{ha}^{-1}$ ) and $0.16 \mathrm{~m}$ for the coppice forest scenario (with a basal area equal to $25 \mathrm{~m}^{2} \mathrm{ha}^{-1}$ ).

At the end of each test, several geometric characteristics of the deposits were measured, specifically the maximum distance reached by the debris flow from the flume outlet, $R$; the total travel distance, $L$; the elevation difference between the starting point and the lowest point of deposition of the mass movement, $H$; the flooded area, $A$; the maximum deposit thickness, $t$; and the mass and volume of the deposited material, $P_{\text {dep }}$ and $V_{\text {dep }}$, respectively.

Each run was recorded with a video camera located at the end of the storage surface. The frames were extracted from the videos to back-calculate the mean velocities of the flow in the flume and at the flume outlet, $U_{\text {out }}$, following the procedure described by Bettella et al. (2015).

Finally, a linear regression model was proposed to predict debris-flow mobility that is based on the solid volumetric concentration of the debris flow and the presence of forests on the fan.

\section{Results}

The small-scale laboratory experiments were performed in order to observe the effects of the presence of elements in the fan area on debris-flow mobility. Twenty-nine debris-flow runs were performed under three scenarios and with four solid volumetric concentrations each ( $C_{\mathrm{V}}$ equal to $0.50,0.55,0.60$, and 0.65$)$.

\section{Dimensionless characterisation of flow regime}

Our debris-flow runs exhibited Bagnold numbers $N B>200$ (a value $<200$ was noted in only one run); thus, collisional forces dominate the viscous forces, according to Iverson (1997). Most of the runs (19 data) have Savage numbers $N S>0.1$; thus, collisional forces dominate the frictional forces. Most of the runs (25 data) show $N F>2000$ and $N B>100$; thus, frictional forces dominate the viscous forces. In our laboratory tests, therefore, collisional and frictional forces dominate the flow regime.

\section{Flow behaviour and morphometric parameters of the deposits}

Generally, the deposits exhibited an elongated ellipsoidal lobe with a well-defined front. No bifurcation of the front was observed during the tests. Segregation and accumulation of coarse particles were observed in the distal part of the deposit, as also observed by Hürlimann et al. (2015) in their laboratory experiments. An overview of the morphological features measured after each run are listed in Table 3 and plotted in Figure 3, together with the mean deposit width $W$, the debris-flow velocities at the flume outlet ( $U_{\text {out}}$ ), and the resistance coefficient $H / L$ (Iverson, 1997). $W$ has been calculated as the ratio between the flooded area $(A)$ and the maximum runout $(R)$. $U_{\text {out }}$ was back-calculated from inspection of the video frames (as described in Bettella et al., 2015).

$R$ ranged from 0.37 to $1.19 \mathrm{~m}, W$ ranged from 0.34 to $0.52 \mathrm{~m}$, $A$ ranged from 0.14 to $0.47 \mathrm{~m}^{2}, P_{\text {dep }}$ ranged from 2.16 to $6.19 \mathrm{~kg}, t$ ranged from 0.006 to $0.033 \mathrm{~m}, U_{\text {out }}$ ranged from 1.09 to $2.72 \mathrm{~m} \mathrm{~s}^{-1}$, and $H / L$ ranged from 0.29 to 0.39 . The maximum values of $R$ and $A$ were observed for the mixture with $C \mathrm{~V}$ equal to 0.50 in the scenario with no elements. Those tests exhibit also the lower values of $H / L$. The maximum values of $W$ and $t$ were observed for the coppice forest scenario and the mixture with $C_{V}$ equal to 0.65 . The minimum values of $R$ and $A$, and the maximum values of $H / L$ were observed in the coppice forest scenario using a mixture with a $C \mathrm{~V}$ equal to 0.65 . The highest $C_{\mathrm{V}}$ also produced the minimum velocities, and the minimum value of $W$ was observed in the scenario without elements for a mixture with $C_{V}$ equal to 0.60 . Finally, mixtures with low $C_{\mathrm{V}}$ show the minimum values of $P_{\text {dep }}$ in a simulation with a coppice forest and $t$ in a simulation with no elements. The scatterplots of the main variables are reported in Figure 4.

\section{Effect of vegetation}

A comparison of the morphological characteristics of the deposits for the three scenarios is reported in Figure 4. Scatterplots indicate also the effect of the volumetric solid concentration of the mixture. Although increases in the solid phase led to smaller values of $R$ in all configurations, the scenarios with coppice forest elements showed a greater rate of decrease than the runs without elements. This was observed also for $A$ and $U_{\text {out. The opposite behav- }}$ ior was observed for the variables $H / L, t$ and $P_{\text {dep }}$, whereas $W$ does not show significant changes (Figure 3 ). Differently from coppice forest, high forest scenario does not exhibit a clear behavior: only the variables $A$ and $P_{\text {dep }}$ show a significant correlation with $C_{\mathrm{V}}$, and the main parameters which describes the flow resistance induced by the presence of the elements (such as $R$ and $H / L$ ) does not present significant linear relationships with $C_{\mathrm{V}}$.

Linear relationships were not found for all the analysed variables to be function of $C_{\mathrm{V}}$. Observing the scatterplots in Figure 4, it is possible to note that the coppice forest scenario has greater rates of change than the high forest scenario for the morphological variables investigated. Compared with the runs without elements, $R$ decreased on average by $9.8 \%$ for the high forest configuration and by $21.0 \%$ for the coppice forest configuration. Particularly in the coppice forest scenario, smaller values of $R$ generally corresponded to greater values of $W$ and $t$ and smaller values of $A$ compared to a free surface. On average, $W$ increased, with respect to the runs without elements, by $12.2 \%$ for the high forest configuration and by $13.0 \%$ for the coppice forest configuration. The sediment thickness $t$ increased on average by $35.7 \%$ under the high forest configuration and by $78.9 \%$ under the coppice forest configuration. The maximum change in the first case was observed for $C_{\mathrm{V}}=0.50$, whereas the maximum change was observed for $C_{\mathrm{V}}=0.55$ in the second case.

The reduction in $A$ was more evident using coppice-like elements, with an average reduction of $10.3 \%$ with respect to the scenario without elements. The reduction was emphasised in the runs with the lowest water contents (a reduction of 33.1\% was noted for $C_{\mathrm{V}}=0.65$ ). Similarly, high forest-like elements seem to cause a reduction in deposit size only in the case of solid-dominated debris flows (a reduction in $A$ of $21.6 \%$ with respect to the scenario without elements was noted for $C_{\mathrm{V}}=0.65$ ).

Table 2. Forest-stand characteristics (forest density, diameter at breast height, and basal area) resulting from the small-scale laboratory experiments in the flume, assuming a geometrical scale of $1: 50$.

\begin{tabular}{lccc} 
Scenario & $\begin{array}{c}\text { Forest density } \\
(\mathrm{n} \mathrm{ha-1})\end{array}$ & $\begin{array}{c}\text { DBH } \\
(\mathrm{m})\end{array}$ & $\begin{array}{c}\text { Basal area } \\
\left(\mathrm{m}^{2} \mathrm{ha}^{-1}\right)\end{array}$ \\
High forest & 400 & 0.30 & 28 \\
Coppice & 400 & 0.16 & 25 \\
\hline
\end{tabular}




\section{Discussion}

The distance that a debris flow can travel depends significantly on the mechanical characteristics of the debris, as well as its total volume, the channel geometry and the bed inclination (Ancey, 2001). The alluvial fan is the preferential area for debris-flow deposition, owing to the decrease in bed slope and widening of the channel. In addition, in many cases, when a debris flow reaches an area with gentle slopes, it overflows the channel banks, spreads out, reduces its momentum and then stops (Tsai, 2006). The results of our laboratory experiments suggest that forest buffers within fan areas can reduce debris-flow mobility, providing additional resistance and hindering the flow motion. In general, shorter runouts and larger deposit widths were observed for the high forest and coppice forest scenarios. The elements in the fan area intercept part of the debris-flow material, reducing its energy and mobility
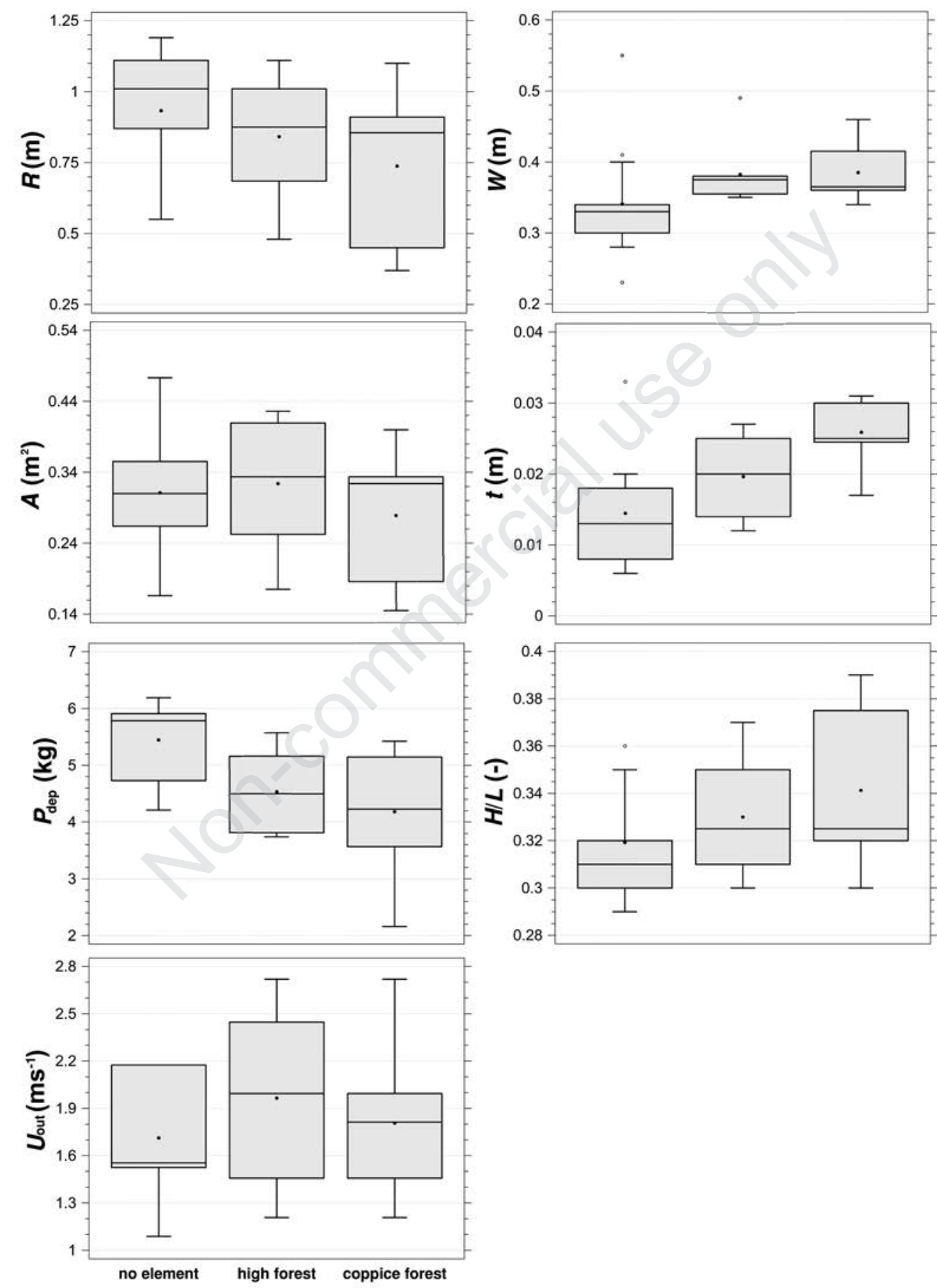

Figure 3. Box-and-whisker plots of the parameters measured after each run: the maximum runout on the depositional plane $(R)$, the mean deposit width $(W)$, the flooded area $(A)$, the maximum deposit thickness $(t)$, the mass of deposited material $\left(P_{d e p}\right)$, the resistance coefficient $H / L$, and the velocity at the flume outlet $\left(U_{o u t}\right)$. 
Table 3. Overview of the morphological features of the deposits and apex velocity gauged after each run with minimum, maximum, mean values and standard deviation for the three scenarios and the whole dataset (see caption of Figure 3 for symbols).

\begin{tabular}{|c|c|c|c|c|c|c|c|c|c|}
\hline ID & Scenario & $\begin{array}{l}C_{V} \\
(-)\end{array}$ & $\begin{array}{c}R \\
(\mathrm{~m})\end{array}$ & $\begin{array}{c}W \\
(\mathrm{~m})\end{array}$ & $\begin{array}{c}A \\
\left(\mathrm{~m}^{2}\right)\end{array}$ & $\begin{array}{l}P_{\text {dep }} \\
(\mathrm{kg})\end{array}$ & $\begin{array}{c}t \\
(\mathrm{~m})\end{array}$ & $\begin{array}{c}U_{\text {out }} \\
\left(\mathrm{m} \mathrm{s}^{-1}\right)\end{array}$ & $\begin{array}{c}H / L \\
(-)\end{array}$ \\
\hline 1 & No elements & 0.50 & 1.18 & 0.44 & 0.39 & 4.59 & 0.006 & 2.18 & 0.30 \\
\hline 2 & No elements & 0.55 & 1.01 & 0.45 & 0.31 & 4.73 & 0.008 & 1.86 & 0.31 \\
\hline 3 & No elements & 0.60 & 0.93 & 0.34 & 0.26 & 5.79 & 0.018 & 1.55 & 0.32 \\
\hline 4 & No elements & 0.65 & 0.58 & 0.39 & 0.17 & 5.91 & 0.020 & 1.21 & 0.36 \\
\hline 5 & No elements & 0.50 & 1.13 & 0.42 & 0.26 & 4.21 & 0.017 & 2.18 & 0.30 \\
\hline 6 & No elements & 0.55 & 1.05 & 0.39 & 0.34 & 4.64 & 0.011 & 1.86 & 0.31 \\
\hline 7 & No elements & 0.60 & 1.02 & 0.35 & 0.31 & 5.84 & 0.008 & 1.53 & 0.31 \\
\hline 8 & No elements & 0.65 & 0.60 & 0.35 & 0.33 & 6.10 & 0.033 & 1.36 & 0.35 \\
\hline 9 & No elements & 0.50 & 1.19 & 0.42 & 0.47 & 5.30 & 0.010 & 2.18 & 0.29 \\
\hline 10 & No elements & 0.55 & 1.11 & 0.41 & 0.36 & 5.80 & 0.008 & 2.18 & 0.30 \\
\hline 11 & No elements & 0.60 & 0.87 & 0.38 & 0.36 & 6.19 & 0.013 & 1.55 & 0.32 \\
\hline 12 & No elements & 0.65 & 0.55 & 0.37 & 0.18 & 5.93 & 0.020 & 1.09 & 0.36 \\
\hline 13 & No elements & 0.60 & 0.91 & 0.36 & 0.31 & 5.77 & 0.016 & 1.55 & 0.32 \\
\hline \multicolumn{3}{|c|}{ Minimum } & 0.55 & 0.34 & 0.17 & 4.21 & 0.006 & 1.09 & 0.29 \\
\hline \multicolumn{3}{|c|}{ Maximum } & 1.19 & 0.45 & 0.47 & 6.19 & 0.033 & 2.18 & 0.36 \\
\hline \multicolumn{3}{|c|}{ Mean } & 0.93 & 0.39 & 0.31 & 5.45 & 0.014 & 1.71 & 0.32 \\
\hline \multicolumn{3}{|c|}{ Standard deviation } & 0.23 & 0.04 & 0.08 & 0.67 & 0.007 & 0.38 & 0.02 \\
\hline 14 & High forest & 0.55 & 1.05 & 0.46 & 0.39 & 3.80 & 0.015 & 2.72 & 0.31 \\
\hline 15 & High forest & 0.60 & 0.97 & 0.41 & 0.34 & 4.75 & 0.012 & 2.18 & 0.31 \\
\hline 16 & High forest & 0.65 & 0.51 & 0.43 & 0.18 & 5.57 & 0.025 & 1.36 & 0.37 \\
\hline 17 & High forest & 0.55 & 1.11 & 0.44 & 0.43 & 3.74 & 0.013 & 2.72 & 0.30 \\
\hline 18 & High forest & 0.60 & 0.86 & 0.41 & 0.32 & 5.19 & 0.016 & 1.55 & 0.33 \\
\hline 19 & High forest & 0.65 & 0.48 & 0.40 & 0.17 & 5.12 & 0.027 & 1.21 & 0.37 \\
\hline 20 & High forest & 0.50 & 0.86 & 0.47 & 0.42 & 4.25 & 0.024 & 1.81 & 0.33 \\
\hline 21 & High forest & 0.50 & 0.89 & 0.45 & 0.33 & 3.83 & 0.025 & 2.18 & 0.32 \\
\hline \multicolumn{3}{|c|}{ Minimum } & 0.48 & 0.40 & 0.17 & 3.74 & 0.012 & 1.21 & 0.30 \\
\hline \multicolumn{3}{|c|}{ Maximum } & 1.11 & 0.47 & 0.43 & 5.57 & 0.027 & 2.72 & 0.37 \\
\hline \multicolumn{3}{|c|}{ Mean } & 0.84 & 0.43 & 0.32 & 4.53 & 0.020 & 1.97 & 0.33 \\
\hline \multicolumn{3}{|c|}{ Standard deviation } & 0.23 & 0.03 & 0.10 & 0.72 & 0.006 & 0.58 & 0.03 \\
\hline 22 & Coppice forest & 0.65 & 0.43 & 0.40 & 0.14 & 5.38 & 0.030 & 1.21 & 0.38 \\
\hline 23 & Coppice forest & 0.55 & 0.89 & 0.40 & 0.33 & 4.91 & 0.025 & 1.81 & 0.32 \\
\hline 24 & Coppice forest & 0.60 & 0.83 & 0.36 & 0.33 & 4.29 & 0.030 & 1.81 & 0.33 \\
\hline 25 & Coppice forest & 0.50 & 0.93 & 0.43 & 0.33 & 2.16 & 0.025 & 2.72 & 0.32 \\
\hline 26 & Coppice forest & 0.50 & 1.10 & 0.43 & 0.40 & 3.54 & 0.017 & 2.18 & 0.30 \\
\hline 27 & Coppice forest & 0.55 & 0.88 & 0.45 & 0.32 & 4.18 & 0.025 & 1.81 & 0.32 \\
\hline 28 & Coppice forest & 0.60 & 0.47 & 0.42 & 0.21 & 3.60 & 0.024 & 1.55 & 0.37 \\
\hline 29 & Coppice forest & 0.65 & 0.37 & 0.52 & 0.16 & 5.43 & 0.031 & 1.36 & 0.39 \\
\hline \multicolumn{3}{|c|}{ Minimum } & 0.37 & 0.36 & 0.14 & 2.16 & 0.017 & 1.21 & 0.30 \\
\hline \multicolumn{3}{|c|}{ Maximum } & 1.10 & 0.52 & 0.40 & 5.43 & 0.031 & 2.72 & 0.39 \\
\hline \multicolumn{3}{|c|}{ Mean } & 0.74 & 0.43 & 0.28 & 4.18 & 0.026 & 1.81 & 0.34 \\
\hline \multicolumn{3}{|c|}{ Standard deviation } & 0.27 & 0.05 & 0.09 & 1.09 & 0.005 & 0.48 & 0.03 \\
\hline \multicolumn{10}{|c|}{ Statistics of the whole dataset } \\
\hline \multicolumn{3}{|c|}{ Minimum } & 0.37 & 0.34 & 0.14 & 2.16 & 0.006 & 1.09 & 0.29 \\
\hline \multicolumn{3}{|c|}{ Maximum } & 1.19 & 0.52 & 0.47 & 6.19 & 0.033 & 2.72 & 0.39 \\
\hline \multicolumn{3}{|c|}{ Mean } & 0.85 & 0.41 & 0.31 & 4.85 & 0.019 & 1.81 & 0.33 \\
\hline \multicolumn{3}{|c|}{ Standard deviation } & 0.25 & 0.04 & 0.09 & 0.97 & 0.008 & 0.46 & 0.03 \\
\hline
\end{tabular}


according to Lancaster et al. (2003) and Matyja (2007). Moreover, vegetation promotes the formation of a step-like surface on the slope, increasing surface roughness and further affecting the flow. This was observed in particular for the coppice forest runs, in which the distinctive structure of coppice forests, which is provided by the suckers, provides a more effective obstruction action compared to high forest trunks and offers a greater cross-sectional area of interaction with the flow (Figure 5). In fact, the coppices in the laboratory model were composed of eight elements (coppice shoots). They (the coppice stocks) occupied approximately $0.01 \mathrm{~m}$ transverse to the flow direction in the merging zone, a value that increased with the height above the terrain. In contrast, the highforest elements have a constant width of $0.006 \mathrm{~m}$ per element.

In agreement with de Haas et al. (2015), Hürlimann et al. (2015), and Scheidl et al. (2013), the results of this study highlight that small variations in water content are associated with large
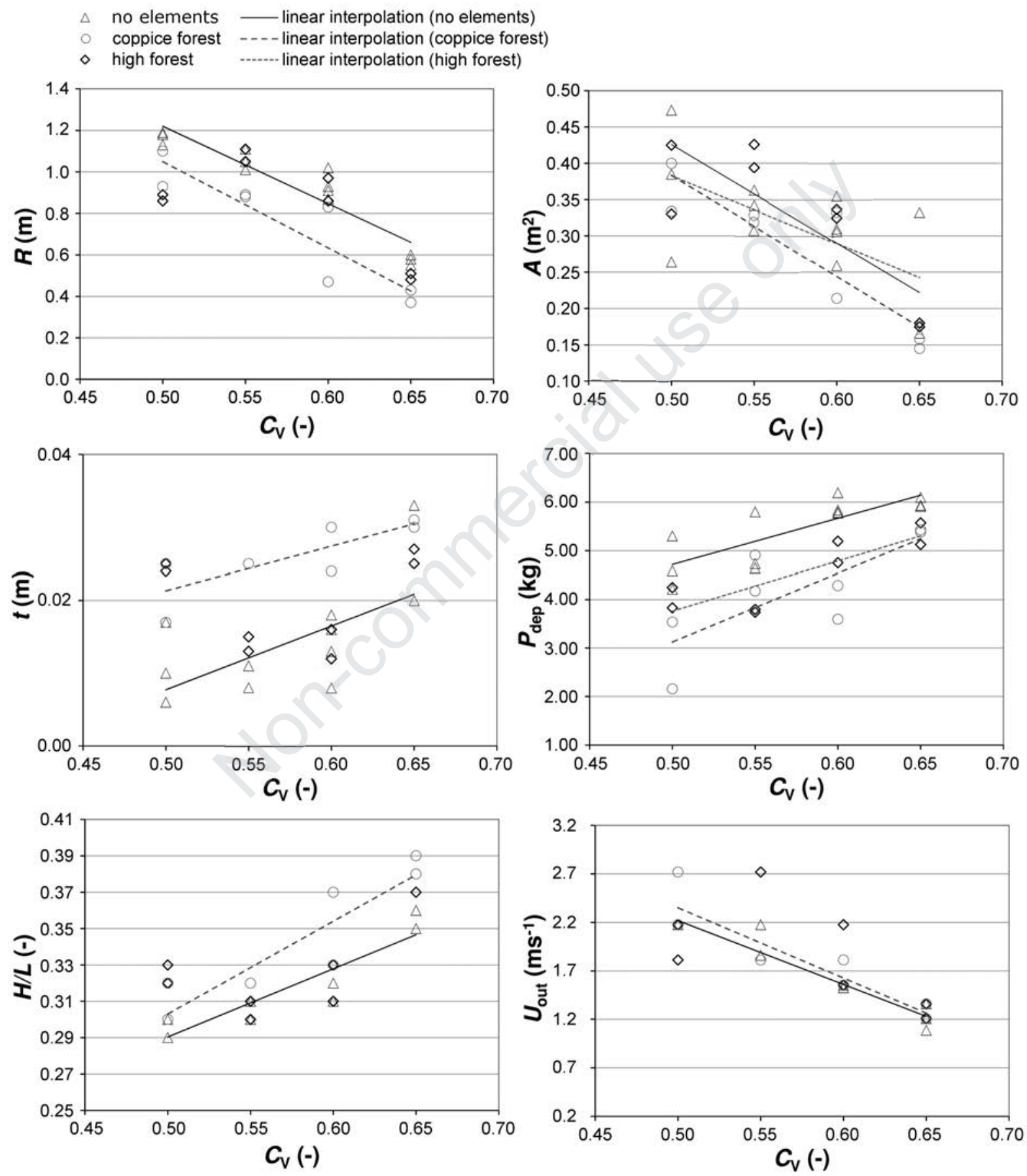

Figure 4. Scatter plots of the variables measured after each run versus the solid volumetric concentration (Cv), and linear fitting of the data (only statistically significant regressions - F-test). 
changes in maximum runout distances. This effect was found especially by Hürlimann et al. (2015) and D'Agostino et al. (2013) using grain-size distributions containing relatively small amounts of clay and silt, similar to the mixture material used during our tests. We observed that, on average, a 15\% increase in the volumetric water fraction (corresponding to a change in liquid volumetric concentration $C_{\mathrm{W}}$ from 0.35 to 0.50 ) causes runout distances to more than double. Volumetric concentration also affects the effect of vegetation. Actually, high-forest management seems not able to reduce debris-flow motion at the highest solid concentrations, whereas some higher reduction is noted for the lowest concentrations. In contrast, the coppice forest seems to always provide a notable contribution, which increases with the solid concentration. At the lowest concentration $\left(C_{\mathrm{V}}=0.50\right)$, the high forest and coppice forest yielded similar reductions in $R$ with respect to the scenario without elements. On the other hand, at the highest concentration, the coppice forest offered a reduction in $R$ values that was about two times greater than that of the high forest. Due to the dataset size, a statistical analysis to confirm these statements could not be performed. To this end, additional tests are required.

Nevertheless, coppice forests seem to offer an improved protective function. Our interpretation is that coppice stocks manifest a more effective obstruction action compared to high forest trunks. Actually, at higher volumetric concentration values of the mixtures, the particles floating in the matrix are easily trapped by the upper part of the simulated coppice forest, and the stems work as an effective filtering rake in blocking the solid material. At lower

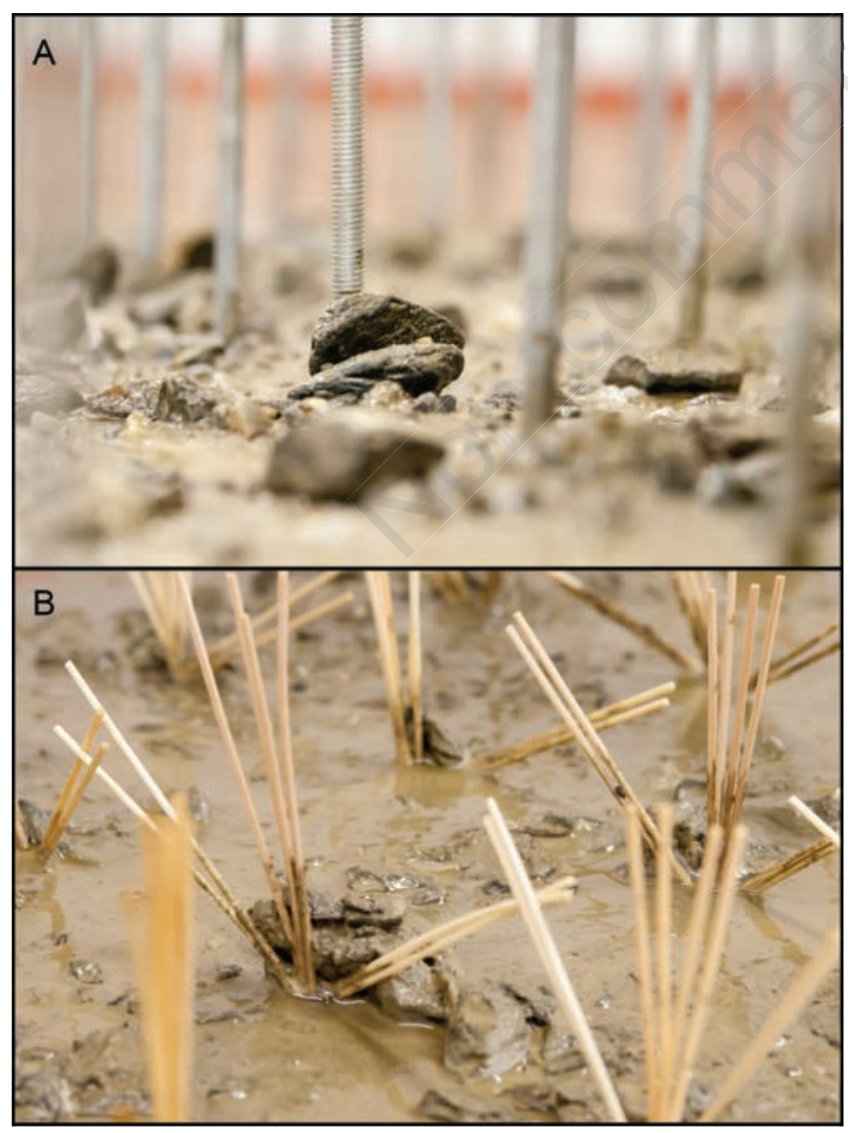

Figure 5. Sediment particles stopped behind high forest (A) and coppice forest $(B)$ vertical elements. concentrations, the magnitude of this effect is reduced because of the lower flow depths, and the debris-flow tail exerts a sort of washout effect on the sediments previously deposited behind the elements. Additionally, we noted that high-forest elements only stop larger particles, whereas coppice elements have a less grain size selective effect (Figure 5).

$U_{\text {out }}$ can be assumed the main energetic driver conditioning the runout phase. Figure 6 shows how the energy of the flow at the outlet of the flume (described by the kinetic head $U^{2}$ out $/ 2 g$ ) affects the runout distance. Data are grouped in no elements scenario and with elements scenario. The last one includes high forest and coppice forest data because no significant differences were found within this analysis. The vegetation effect in reducing the runout distance is clear: the scenario with vegetation guarantees lower runout values in proportion to the kinematic load. Considering the logarithmic interpolations of Figure 6, the presence of elements in the fan area ensures an average $R$ reduction of the $22.1 \%$. The relative reduction is larger for the lower values of $U^{2}$ out $/ 2 g$ (equal to $27.0 \%$ for $U^{2}$ out $/ 2 g=0.08 \mathrm{~m}$ ), decreasing with the increase of the energy at the outlet of the flume (equal to $19.2 \%$ for $U^{2}$ out $/ 2 g=0.38 \mathrm{~m}$ ).

This finding suggested the calibration of empirical predictive models for $H / L\left(\mathrm{~m} \mathrm{~m}^{-1}\right)$ that are a function of the forest type and the solid concentration of the mixture $C_{V}$. The $H / L$ ratio (the inverse of $L / H$ ) indicates a resistance coefficient, and it was one of the earliest dimensionless variables used to quantify the potential travel distance of gravitational phenomena (Heim, 1882). The resulting linear regression models describing the relationship between $H / L$ and $C_{V}$ are graphically reported in Figure 4. The equations are as follows:

$$
\begin{array}{ll}
\text { No elements } & \mathrm{H} / \mathrm{L}=0.103+0.375 C_{V} \\
\text { Coppice forest } & \mathrm{H} / \mathrm{L}=0.048+0.51 C_{V}
\end{array}
$$

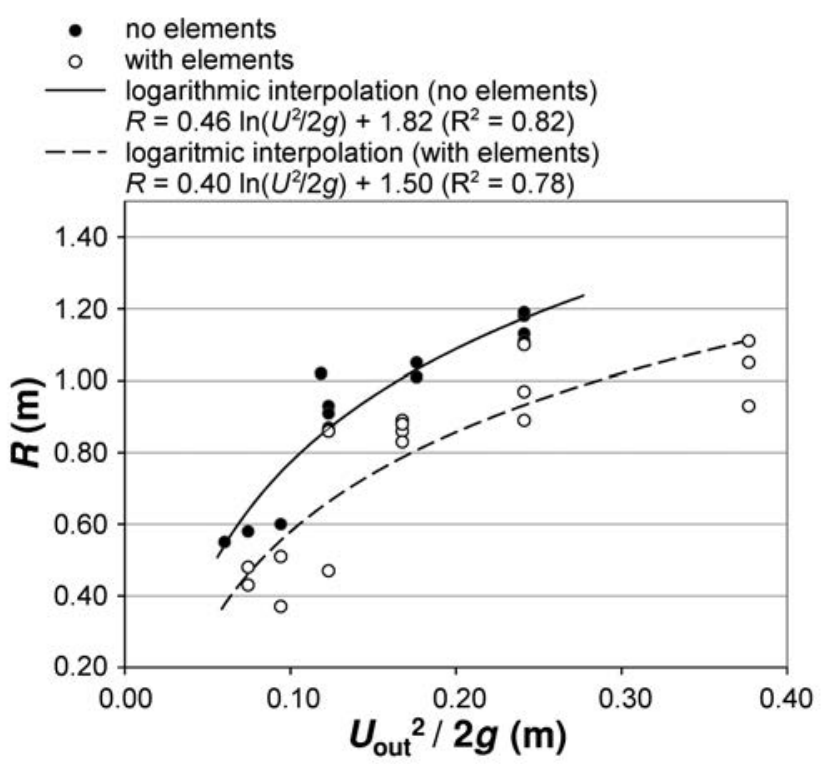

Figure 6. Relationships between kinematic load $\left(\mathrm{U}^{2}\right.$ out $\left./ 2 g\right)$ and runout distance $(\mathrm{R})$ for the no elements and with elements scenarios (this last one includes high forest and coppice forest data). 
No model is presented for the high forest scenario because no significant linear relationship was found. Effectively, this scenario exhibits, for $0.50 \leq C_{\mathrm{V}} \leq 0.60, H / L$ ratio ranging from 0.30 to $0.33 \mathrm{~m}$ $\mathrm{m}^{-1}$, similarly to the no element scenario. Only the tests with $C_{\mathrm{V}}=0.65$ exhibit higher $H / L$ values. This behavior is probably caused by the effect of other variables such as $P_{\text {dep }}$ and $U_{\text {out, }}$, indicating $C_{\mathrm{V}}$ is not fully exhaustive in predicting $H / L$ by itself. The adjusted R-squared statistic indicates that the fitted models are able to explain $82.3 \%$ and $82.4 \%$ of the variance in $H / L$ respectively for the no elements and coppice forest scenarios. These equations confirm that the presence of a coppice forest causes the runout process to be more sensitive to changes in $C_{\mathrm{V}}$, and the effect is greatest at the highest $C_{\mathrm{V}}$ values. The presented equations are fully empirical and are based only on our small-scale laboratory tests. As a consequence, additional work is needed to investigate their validity at the actual scale, especially through field data collection.

\section{Conclusions}

The depositional process was investigated on 29 small-scale debris flows that were generated in the laboratory in order to study the effects of forests on the features of debris-flow deposits and particularly the ability of forests to reduce debris-flow motion. The morphological features of the deposits were analysed for smallscale debris flows that occurred on a depositional plane with three configurations, specifically: i) a free depositional surface (i.e., without elements); ii) the presence of elements distributed on a grid on the depositional surface to simulate a high forest; iii) the presence of groups of flexible elements on the depositional surface to simulate a coppice forest.

The upscaled physical parameters of the tests yielded results that are within the ranges of values typical of real debris flows, as well as the relevant dimensionless parameters (i.e., the Savage, Bagnold and Friction numbers). Analysis of the results obtained in the experiments showed that the presence of elements within the fan area causes changes in the deposit shape, generally reducing the runouts and increasing the deposit thickness, although the sediment concentration of the flow remains the key factor that determines the geometry of the deposits. In addition, sediment concentration affects the ability of forests to hinder debris-flow motion. More precisely, the high-forest management type seems to not be able to contribute significantly to reducing debris-flow motion for the highest solid concentrations $\left(C_{V} \geq 0.60\right)$, whereas low contributions were observed for the lowest concentrations $\left(C_{V} \leq 0.55\right)$. In contrast, coppice forests seem to provide a notable contribution to reducing the motion, which increases with the solid concentration. Thanks to their higher density, the coppice stocks seem to provide a better protective function than the high-forest rigid trunks. The sediment volumetric concentration of the debris flow and the type of forest existing on the fan were used to define an empirical predictive model to assess the $H / L$ ratio.

Finally, by analysing the energy dissipation process, we found that the runout distance is reduced on average by $20 \%$ in presence of vegetation (high forest or coppice forest).

In conclusion, this study highlighted that forests might offer a natural complement to debris-flow control structures in depositional areas, preserving the natural landscape or reducing the impact of the artificial control structures. The effect of forests, however, depends on the type of forest management (high forest or coppice forest) and the volumetric concentration of the debris flow. In general, coppice forests seem to be more effective, regardless of the volumetric concentration, whereas the effects of high forests seem to be significant only at lower concentrations. To confirm these findings, more work is needed to further investigate the validity of the identified behaviours and relationships, especially through field data collection.

\section{References}

Ancey C. 2001. Debris flows and related phenomena. Lecture Notes Physics 21:528-47.

Berti M., Simoni A. 2007. Prediction of debris flow inundation areas using empirical mobility relationships. Geomorphology 90:144-61.

Bettella F., Bischetti G.B., D’Agostino V., Marai S.V., Ferrari E., Michelini T. 2015. Comparison of measurement methods of the front velocity of small-scale debris flows. J. Agricult. Engine. 46:129-37.

Brang P., Schönenberger W., Frehner M., Schwitter R., Wasser B. 2006. Management of protection forests in the European Alps: an overview. For. Snow Landsc. Res. 80:23-44.

Coussot P., Proust S. 1996. Slow, unconfined spreading of a mudflow. J. Geophys. Res. Solid Earth 101:25217-29.

D’Agostino V., Bettella F., Cesca M. 2013. Basal shear stress of debris flow in the runout phase. Geomorphology 201:272-80.

D’Agostino V., Cesca M., Marchi L. 2010. Field and laboratory investigation on runout distances of debris flows in Dolomites (Eastern Italian Alps). Geomorphology 115:294-304.

de Haas T., Braat L., Leuven J.R.F.W., Lokhorst I.R., Kleinhans M.G. 2015. Effects of debris flow composition on runout, depositional mechanisms, and deposit morphology in laboratory experiments. J. Geophys. Res. Earth Surf. 120:1949-72.

Fidej G., Mikoš M., Rugani T., Jež J., Kumelj S., Diaci J. 2015. Assessment of the protective function of forests against debris flows in a gorge of the Slovenian Alps. Forest Biogeosci. Forest. 8:73-81.

Guthrie R.H., Hockin A., Colquhoun L., Nagy T., Evans S.G., Ayles C. 2010. An examination of controls on debris flow mobility: evidence from coastal British Columbia. Geomorphology 114:601-13.

Hürlimann M., McArdell B.W., Rickli C. 2015. Field and laboratory analysis of the runout characteristics of hillslope debris flows in Switzerland. Geomorphology 232:20-32.

Hutchinson J.N. 1986. A sliding-consolidation model for flow slides. Canad. Geotechn. J. 23:115-26.

Ishikawa N., Inoue R., Hayashi K., Hasegawa Y., Mizuyama T. 2008. Experimental approach on measurement of impulsive fluid force using debris flow model. INTERPRAEVENT 2008 - Conference Proceedings, Vol. 1, pp. 343-354, available from: http://www.interpraevent.at/palm-cms/upload_files/ Publikationen/Tagungsbeitraege/2008_1_343.pdf

Ishikawa Y., Kawakami S., Morimoto C., Mizuhara K. 2003. Suppression of debris movement by forests and damage to forests by debris deposition. J. For. Res. 8:37-47.

Iverson R.M. 1997. The physics of debris flows. Rev. Geophys. $35: 245$.

Iverson R.M. 2015. Scaling and design of landslide and debrisflow experiments. Geomorphology 244:9-20.

Iverson R.M., Logan M., Lahusen R.G., Berti M. 2010. The perfect debris flow? Aggregated results from 28 large-scale experiments. J. Geophys. Res. 115:F03005.

Lancaster S.T., Hayes S.K., Grant G.E. 2003. Effects of wood on 
debris flow runout in small mountain watersheds. Water Resour. Res. 39:1168.

Major J.J., Iverson R.M. 1999. Debris-flow deposition: effects of pore-fluid pressure and friction concentrated at flow margins. Geol. Soc. Am. Bull. 110:1424-34.

Matyja M. 2007. The significance of trees and coarse woody debris in shaping the debris flow accumulation zone (North slope of the Babia Góra Massif, Poland). Geograph. Pol. 80:83.

May C.L. 2002. Debris flows through different forest age classes in the central Oregon Coast Range. J. Am. Water Resour. Assoc. 38:1097-113.

Michelini T., Bettella F., D’Agostino V. 2016. Field investigations of the interaction between debris flows and forest vegetation in two Alpine fans. Geomorphol. 279:150-64.

Parsons J.D., Whipple K.X., Simoni A. 2001. Experimental study of the grain-flow, fluid-mud transition in debris flows. J. Geology 109:427-47.

Rickenmann D. 2005. Runout prediction methods. In: M. Jakob and O. Hungr (Eds.), Debris-flow hazards and related phenomena. Springer, Berlin, Germany, pp. 305-324.
Rickenmann D. 1999. Empirical relationships for debris flows. Nat. Hazards 19:47-77.

Roering J.J., Schmidt K.M., Stock J.D., Dietrich W.E., Montgomery D.R. 2003. Shallow landsliding, root reinforcement, and the spatial distribution of trees in the Oregon Coast Range. Can. Geotech. J. 40:237-53.

Scheidl C., Chiari M., Kaitna R., Müllegger M., Krawtschuk A., Zimmermann T., Proske D. 2013. Analysing debris-flow impact models, based on a small scale modelling approach. Surv. Geophys. 34:121-40.

Schmidt K.M., Roering J.J., Stock J.D., Dietrich W.E., Montgomery D.R., Schaub T. 2001. The variability of root cohesion as an influence on shallow landslide susceptibility in the Oregon Coast Range. Can. Geotech. J. 38:995-1024.

Takahashi T. 1991. Debris flow. IAHR Monograph Series. Balkema Publishers, The Netherlands.

Tsai M.P., Hsu Y.C., Li H.C., Shu H.M., Liu K.F. 2006. Application of simulation technique on debris flow hazard zone delineation: a case study in the Daniao tribe, Eastern Taiwan. Nat. Hazards Earth Syst. Sci. 11:3053-62. 